\title{
El discurso anticlerical en Fernando Vallejo, o cómo narrar sin religión
}

The anti-clerical discourse of Fernando Vallejo, or how to narrate without religion

O discurso anticlerical em Fernando Vallejo, ou como narrar sem religião

\section{Aníbal González}

YALE UNIVERSITY, ESTADOS UNIDOS

Profesor del Departamento de Español y Portugués de Yale University,

Estados Unidos. PhD en Literatura por la misma universidad. Autor

de La crónica modernista hispanoamericana (Porrúa Turanzas, 1983),

La novela modernista hispanoamericana (Gredos, 1987), fournalism

and the Development of Spanish American Narrative (Cambridge

University Press, 1993), Abusos y admoniciones: ética y escritura en la

narrativa hispanoamericana moderna (Siglo XXI, 2001; versión al

inglés: Killer Books: Violence, Writing, and Ethics in Modern Spanish

American Narrative; University of Texas Press, 2002), A Companion

to Spanish American Modernism (Támesis, 2007), Love and Politics

in the Contemporary Spanish American Novel (University of Texas

Press, 2010) y una edición comentada de la novela Redentores, de

Manuel Zeno Gandía, en la Editorial de la Universidad de Puerto

Rico (2010). Correo electrónico: anibal.gonzalez@yale.edu

Artículo de reflexión

Este ensayo es parte de un libro en preparación sobre la religión en la novela hispanoamericana contemporánea. Documento accesible en línea desde la siguiente dirección: http://revistas.javeriana.edu.co 


\section{Resumen}

Este artículo estudia el papel de lo sagrado y la religión en el desarrollo de la novela hispanoamericana. González examina la narrativa de Vallejo como parte de las narrativas desacralizadoras del posboom que respondieron a las novelas enciclopédicas y totalizadoras del boom y se resistieron a la tendencia moderna de hacer de los textos literarios textos sagrados, fuentes de revelación de saberes trascendentes sobre los orígenes de la nación. Por medio de su reflexión sobre las manifestaciones estéticas de la desacralización en Vallejo, González no solo sitúa a Vallejo en el contexto más amplio de la literatura hispanoamericana, sino que aporta también una manera de aproximarse a sus posturas antirreligiosas.

Palabras clave: literatura latinoamericana, Fernando Vallejo, posboom, religión, modernismo

\section{Abstract}

This article studies the roles of what is sacred and religious as per the development of Latin American novel. González analyzes Vallejo's narrative as part of the postboom demystifying narratives which were a response to the encyclopedic and totalizing novels of the boom, by resisting the modern tendency to turn literary texts into sacred ones, sources of revelation of transcending knowledge about the origins of the nation. Through his reflection on the aesthetic manifestations of demystification in Vallejo, González not only places Vallejo in the widest context of Latin American literature but makes a contribution as per one way to approach his anti-religious stances.

Key words: Latin American literature; Fernando Vallejo; post-boom; religion; modernism

\section{Resumo}

Este artigo estuda o papel do sagrado e da religião no desenvolvimento da novela hispano-americana. González examina a escritura de Vallejo como parte das narrativas dessacralizadoras do pós-boom. Estas últimas responderam às novelas enciclopédicas e totalizadoras do boom, resistindo à tendência moderna de fazer dos textos literários textos sagrados, fontes de revelação de saberes transcendentes sobre as origens da nação. Através de sua reflexão sobre as manifestações estéticas da dessacralização em Vallejo, González não somente situa o escritor no contexto mais amplo da literatura hispano-americana, como também apresenta uma maneira de aproximar-se a suas posturas antirreligiosas.

Palavras-chave: Literatura Latino-Americana; Fernando Vallejo; pós-boom; religião; modernismo

RECIBIDO: 2 DE MARZO DE 2014. EVALUADO: 29 DE MARZO DE 2014. DISPONIBLE EN LÍNEA: 15 DE ENERO DE 2015.

\section{Cómo citar este artículo:}

González, Aníbal. "El discurso anticlerical en Fernando Vallejo, o cómo narrar sin religión". Cuadernos de Literatura 19. 37 (2015): 122-135. doi:10.11144/Javeriana.CL19-37.edaf 
"La 'razón' en el lenguaje: ¡oh qué vieja hembra estafadora! Me temo que no nos libraremos de Dios mientras sigamos creyendo en la gramática..."

FRIEDRICH NIETZSCHE, El crepúsculo de los ídolos

EN HONOR A la verdad, debo confesar de inmediato que el subtítulo de este trabajo - cómo narrar sin religión — promete algo que quizás sea imposible, como sugiere el epígrafe de Nietzsche y como lo demuestra en la práctica la narrativa de Fernando Vallejo. A primera vista, parecería que el autor colombiano premiado en la Feria Internacional del Libro de Guadalajara en el 2011 también se podría llevar el premio (si lo hubiera) para el más irreligioso o incluso más antirreligioso de los escritores contemporáneos en cualquier lengua. ¿Más que Salman Rushdie, con sus Versos satánicos (1988), que casi le cuestan la vida? ¿Más que Richard Dawkins, cuyo libro The God Delusion (2006) compendia todos los argumentos contra la existencia de Dios y en favor de la superioridad moral del ateísmo? ¿Más que el fallecido polemista Christopher Hitchens, con quien quizás tiene el mayor parecido? Tal vez no tanto, como se verá enseguida, pero no es porque no lo haya intentado. De hecho, me propongo argumentar que uno de los aportes más novedosos de la novelística de Vallejo es el experimento que se hace en ella de forjar una narrativa desacralizada y, todavía más, una narrativa que se resiste a ser sacralizada aún por sus lectores más devotos.

En su ensayo de 1951, "Del culto de los libros", contrastando el privilegio de la oralidad en las culturas antiguas con el respeto por la palabra escrita en la era moderna,Jorge Luis Borges observó: "Un libro, cualquier libro, es para nosotros un objeto sagrado" (Obras completas II 91). Incitado por esta aseveración, me he dedicado desde hace algunos años a examinar el papel de lo sagrado y la religión en el desarrollo de la novela hispanoamericana. Es cierto que hablar sobre el vínculo entre la novela y la religión podría parecer contradictorio o paradójico, dado el carácter predominantemente secular de la prosa de ficción en Occidente. Aunque la religión y la poesía siempre han estado entrelazadas visiblemente y de manera armoniosa, no ha sucedido lo mismo con la novela, hecho que llevó al crítico húngaro Georg Lukács a observar que "la novela es la epopeya de un mundo sin dioses" (93). En años más recientes, el novelista italiano Roberto Calasso, elaborando sobre la idea de Lukács, ha dicho con elegancia: "los dioses son los huéspedes fugitivos de la literatura" (1). A pesar de la existencia de algunas narraciones doctrinales de carácter alegórico, como el Pilgrim's Progress (1678), de John Bunyan, en Inglaterra, de novelas picarescas moralizantes como el $G u z$ mán de Alfarache (1604) de Mateo Alemán, en España, o las hagiografías o vidas 
de santos y beatos (que forman un género aparte), no hay propiamente novelas o cuentos escritos "a lo divino" como fácilmente se hizo con la poesía de Garcilaso de la Vega y de tantos otros poetas líricos seculares del Renacimiento. Más preocupada con las dudas, errores e incertidumbres del "reino de este mundo" que con la certeza de una vida ultraterrena, la novela, al ocuparse de asuntos religiosos - como ha sucedido en muchas ocasiones, desde el clérigo avaro del Lazarillo de Tormes y el cura quemador de novelas de caballerías en el Quijote-, lo ha hecho desde la perspectiva crítica de la modernidad y ha privilegiado aquello que se puede ver y conocer, contar y medir, contraponiendo las esferas de lo ideal y lo real, lo sagrado y lo profano.

No obstante, pese a sus orígenes decididamente seculares, a medida que la novela va alcanzando su madurez, también se va revistiendo de aspectos que la acercan a lo sagrado. En particular me interesa el fenómeno del aprovechamiento estético de la religión para dotar a la novela de una mayor trascendencia artística, intelectual e, incluso, espiritual. Me he propuesto estudiar cómo un sector significativo de la novela hispanoamericana se lanzó, desde fines del siglo XIX hasta fines del siglo XX, al intento de hacer de la novela algo más que un testimonio histórico o un objeto de admiración estética para convertirla, en cambio, en algo muy semejante a un texto sagrado - es decir, un texto que ofrece una revelación trascendente acerca de la realidad-.

No utilizo este término - texto sagrado - simplemente en un sentido metafórico. A mi modo de ver, durante algunas décadas del siglo Xx, y en numerosos países, los novelistas de verdad aspiraron - por motivos estéticos, no religiosos-a darles a sus obras el carácter y los atributos de un texto sagrado. Para ello, la novela asimiló críticamente en su constitución toda una gama de experiencias y conceptos religiosos, desde el propio concepto de "lo sagrado" hasta ideas como la creación, la eternidad, la creencia o la fe, la profecía y la vida después de la muerte.

En Religious Experience and the Modernist Novel, Pericles Lewis ha hecho observaciones parecidas con respecto a los novelistas del High Modernism europeo y angloamericano, como Henry James, Marcel Proust, Franz Kafka y Virginia Woolf. Lewis señala que, en la transición al siglo XX, al calor de las investigaciones científicas sobre el impulso religioso hechas por pensadores como William James, Emile Durkheim, Sigmund Freud y Max Weber, y reaccionando a la creciente secularización de sus sociedades, los novelistas agnósticos o ateos de la vanguardia angloeuropea se dedicaron a experimentar con la estructura de la novela para hacer que esta describiera experiencias trascendentes. Aclara Lewis que estos novelistas entendían la "trascendencia" como experiencias del mundo cotidiano que producían intuiciones extraordinarias acerca de la realidad, aunque a menudo 
utilizaban términos religiosos para referirse a ellas, como sucede con el vocablo epifanía, en James Joyce. Según apunta Lewis: "The modernists sought a secular sacred, a form of transcendent or ultimate meaning to be discovered in this world, without reference to the supernatural" (19-21).

A finales del siglo XIX y principios del XX, señala Lewis, el género de la novela comienza a incorporar en su constitución, de modo deliberado y autoconsciente, la idea de lo sagrado. Sin embargo, hubo también diferencias importantes en el modo en que esto ocurrió en distintas regiones del mundo: los modernists europeos, como subraya Lewis, enfocaron su búsqueda de lo sagrado no en la experiencia colectiva ni de los sucesos extraordinarios, sino en la experiencia individual y cotidiana, a fin de describir lo que Virginia Woolf llamó "an ordinary mind on an ordinary day" (Lewis 22). ${ }^{1}$ De ahí el uso prominente por parte de estos escritores de técnicas como el monólogo interior, el fluir de conciencia y el acendrado descriptivismo al que se refería Ortega y Gasset en Ideas sobre la novela cuando señalaba que en Proust "la novela queda reducida [...] a pura descripción inmóvil" (Meditaciones del Quijote e ideas sobre la novela 176). De ahí, además, el relieve de "la novela moderna" en el psicologismo, como observa Ortega al postular que esta novelística se basa en "la psicología imaginaria" y "la invención de almas interesantes" $(199,202)$.

En cambio, la narrativa vanguardista hispánica e hispanoamericana durante las décadas de los veinte y de los treinta va evolucionando a contrapelo de los dictámenes de Ortega de que la novela es un "género moroso" o un "género tupido" $(160,193), y$ tiende a preferir lo que Pérez Firmat llama con acierto una estética neumática para producir novelas "leves, ágiles, incorpóreas" o "gaseiformes" (49). La insistencia sobre la experimentación formal y verbal, y la concepción del arte como juego en novelas de vanguardia en lengua española como El profesor inútil (1926), del español Benjamín Jarnés, o Margarita de niebla (1927), del mexicano Jaime Torres Bodet, las lleva a manifestar de primera mano posturas deliberadamente intrascendentes en las que el interés por lo sagrado no tiene cabida. En poco tiempo, sin embargo, las fuertes presiones sociopolíticas que se ciernen a ambos lados del Atlántico - encarnadas en sucesos que van desde la Revolución Mexicana (1910-1940) hasta la Guerra Civil Española (1936-1939) - van a conducir tanto a los autores que militaron en el vanguardismo como a los que mantuvieron su distancia de este movimiento, a reorientar su enfoque y a buscar darles trascendencia a sus textos vinculándolos con fenómenos más abarcadores y significativos. En este sentido, no fueron pocos los autores para quienes los

1 La cita de Woolf proviene de su ensayo "Modern Fiction" (106). 
dimes y diretes del discurso político, y las diferencias ideológicas que parecían agotarse en consignas, resultaban insuficientes para darle valor y resonancia tanto a la poesía como a la prosa narrativa de aquellos años: desde la poesía de César Vallejo, en Poemas humanos (1938), y de José Gorostiza, en Muerte sin fin (1939), hasta la novelística de Miguel Ángel Asturias, en El señor presidente (escrita en 1933, publicada en 1946) y Alejo Carpentier en ¡Ecué Yamba-O! (1934).

A su vez, el surgimiento de tendencias irracionalistas en la cultura europea tras la debacle de la primera guerra mundial propició el auge del neoprimitivismo en las artes de vanguardia y motivó tanto en Europa como en las Américas una renovada curiosidad artística por la experiencia religiosa y sus efectos en la sociedad y la cultura. Esto se aprecia claramente en el "negrismo", uno de los movimientos vanguardistas de mayor alcance social y literario en Hispanoamérica, del cual Carpentier formó parte. Incluso en la "narrativa de la tierra" hispanoamericana de los años veinte y treinta, pese a su retórica derivada del realismo decimonónico, se observa la postulación de una relación de tipo espiritual, casi panteísta, entre los hispanoamericanos y su tierra, es decir, su entorno geográfico y natural. Como señala Carlos J. Alonso, en la literatura telúrica "the authochtonous Latin American landscape became a privileged literary category, since it was through its constant contact with it that the spiritual essence of the continent's people was shaped" (63).

Todo esto apunta al hecho - ya muy conocido - de que la narrativa hispanoamericana coetánea y un poco posterior a la del High Modernism estaba movida por urgencias mayores que las que movían a las novelas de Joyce, Woolf, Proust o Kafka, pues la crisis de secularización que perturbaba a esos autores escasamente podía parangonarse con las serias cuestiones de fundamentación existencial y legitimidad política y cultural que atormentaban a los hispanoamericanos desde la crisis de la guerra hispano-cubano-norteamericana de 1898. Dicho de otro modo, a los hispanoamericanos les preocupaba mucho menos la "muerte de Dios", proclamada por Nietzsche, que la muerte de la nación —o por lo menos las inestabilidades políticas, sociales y económicas que amenazaban con deshacer unos sentimientos de identidad colectiva que, a principios del siglo XX, llevaban poco más de un siglo de inaugurados-.

La nación - sus orígenes, su destino, sus contornos y definiciones- siguió siendo en gran medida el referente trascendental de las novelas del boom hispanoamericano de los años sesenta, las cuales buscaron, además, renovar el poderío del género novelesco. Se trataba de textos que prometían un saber trascendente sobre los orígenes nacionales y que exigían una lectura devota, atenta, informada por algún tipo de fe; una lectura que era menos una experiencia de placer, que 
un ejercicio ascético de purificación o una prueba iniciática. Enciclopédicas y totalizadoras, estas novelas buscaron causar no solo el escándalo y el asombro, sino también una veneración análoga a la devoción religiosa. Más aún, estas novelas asumieron una misión fundacional en cuanto a la creación de un nuevo discurso sobre la nación. Para cumplir con esa labor fundacional, siguiendo una conocida dialéctica de la modernidad, las "novelas totales" del boom estudiaban y repasaban críticamente al pasado nacional para poder dejarlo atrás e ir así preparando el terreno para un nuevo comienzo. ${ }^{2}$ De ahí el tono escatológico, de fin de época, que caracterizaba tanto a las novelas del boom como a sus modelos del High Modernism, desde las jitanjáforas mortuorias de Finnegans Wake (1939), de Joyce, hasta el final desolador de Cien años de soledad, cuando Macondo es asolado por un "huracán bíblico" (García Márquez 447).

Sin duda, el proceso de sacralización de la novela en la narrativa hispanoamericana llega a su culminación en el boom. La arquitectura de casi todas las obras maestras novelísticas de ese periodo se sostiene sobre elementos derivados de la teología y los textos sagrados. En Rayuela (1964), de Cortázar, se narra con ribetes existencialistas el itinerario intelectual y espiritual de un individuo representativo, un everyman hispanoamericano llamado Horacio Oliveira; mientras que en Cien años de soledad (1967), de García Márquez, se representa el relato colectivo de toda una estirpe mediante el uso abundante y elaborado del discurso profético y de los recursos simbólicos del "realismo mágico". A su vez, en Paradiso (1966), de Lezama Lima, vemos una ambiciosa tentativa de fusionar el discurso novelístico y el religioso a través de la poesía. En gran medida, estas novelas son también discursos sobre la creación del arte, la literatura y la nación, y en todas ellas se narran relatos fundacionales que se proponen como revelaciones acerca de la historia y el destino de Hispanoamérica. Novelas que aspiran a asemejarse a los textos sagrados, estas obras hacen hincapié en la lectura como experiencia iniciática de desciframiento y aprendizaje y exigen de sus lectores la más profunda atención y devoción.

2 Me refiero a la dialéctica de la "autodestrucción innovadora" de la modernidad burguesa que identifica Marshall Berman en su clásico libro All that Is Solid Melts into Air, y que describe del siguiente modo: "The truth of the matter, as Marx sees, is that everything that bourgeois society builds is built to be torn down. 'All that is solid'-from the clothes on our backs to the looms and mills that weave them, to the men and women who work the machines, to the houses and neighborhoods the workers live in, to the firms and corporations that exploit the workers, to the towns and cities and whole regions and even nations that embrace them all-all these are made to be broken tomorrow, smashed or shredded or pulverized or dissolved, so they can be recycled or replaced next week, and the whole process can go on again and again, hopefuly forever, in ever more profitable forms" (99). 
Esta tendencia hacia la sacralización de la novela en la novelística del boom condujo luego, por necesidad, a una tendencia opuesta de desacralización de la novela por parte de las generaciones subsiguientes. Esto se aprecia en las corrientes novelísticas que sucedieron al boom, forjadas por un grupo de autores más jóvenes que llevan a cabo una crítica de las "novelas totales" y exploran una amplia gama de nuevas formas de novelar: Miguel Barnet y Elena Poniatowska inauguran la influyente modalidad de la novela testimonial o documental que se tornaría en el modelo novelístico predominante en la década de los ochenta; Alfredo Bryce Echenique da impulso a una narrativa neosentimental que privilegia la experiencia amorosa; Severo Sarduy y Manuel Puig producen novelas intensamente experimentales y autorreflexivas que deshacen en mayor o menor medida los convencionalismos narrativos del boom, y Mempo Giardinelli y Paco Ignacio Taibo II cultivan la novela de crimen o "novela negra". Ya la crítica se ha ocupado ampliamente de caracterizar esta novelística del posboom y ha enumerado varios de sus rasgos principales, que aparecen en gran medida como la negación de muchos de los rasgos característicos del boom: el rechazo de la totalización y los metarrelatos que buscan explicarlo todo, en favor de narraciones centradas en experiencias individuales; la crítica de los andamiajes genealógicos y del patriarcalismo y elitismo que ellos propician, en favor de relatos centrados en personajes de grupos socialmente marginados (mujeres, homosexuales, grupos étnicos minoritarios); un mayor énfasis en la cultura popular y la llamada cultura de masas, y el rechazo de los procesos de sacralización textual asociados a los artificios del "realismo mágico" y "lo real maravilloso", en favor de una perspectiva desacralizadora y desengañada de la ficción. ${ }^{3}$

3 Para estos comentarios en torno al boom y el posboom, me he beneficiado de los estudios de Gutiérrez-Mouat ("La narrativa latinoamericana del post-boom"), Pellón ("The Spanish American Novel: Recent Developments, 1975 to 1990") y Shaw (Antonio Skármeta and the Post-Boom y The Post-Boom in Spanish American Fiction). A las tres corrientes del posboom que identifica Pellón (la novela testimonio, la novela histórica y la policial, 282), habría que añadir, sin lugar a dudas, las otras dos que señala Shaw (The Post-Boom..., 23-24): la que podría llamarse neovanguardista (de Sarduy a Eltit) y la amorosa-sentimental representada por Bryce Echenique e Isabel Allende. Las críticas al realismo mágico por parte de los escritores del Crack y de MacOndo, que en un principio parecen bastante trasnochadas (el realismo mágico como término y como práctica literaria fue algo de lo que el propio García Márquez se fue alejando a partir de novelas como Crónica de una muerte anunciada), se entienden mejor si las interpretamos como una manera de aludir al aspecto "sagrado" con el que se revisitió a muchas de las novelas del boom. Jorge Volpi ha sido uno de los autores actuales más insistentes sobre este punto. Véanse al respecto sus comentarios en "El profeta de América Latina" (21-6) y El insomnio de Bolívar (67-77). 
No obstante, como es frecuente en el ámbito de las artes, recorrer el camino de la desacralización y el desengaño no fue una pérdida de tiempo, pues no solo hizo de la novelística hispanoamericana una de las tradiciones más influyentes del globo, sino que además condujo a una apreciación más madura y refinada del género por parte de los novelistas de nuestro continente. Sacralizar y desacralizar la novela les ha permitido a los autores y autoras de hoy entender mejor los límites y las posibilidades de este género ante el desafío de las nuevas tecnologías de la comunicación y los nuevos modos de interacción social en un mundo que - para bien o para mal - se encuentra cada vez más vinculado entre sus partes.

La narrativa de Fernando Vallejo ocupa un lugar clave dentro de este contexto de la desacralización de la novela, debido a la elevada visibilidad de sus posturas antirreligiosas en su discurso novelístico. Todo lector de Vallejo ha experimentado el aluvión de diatribas contra la Iglesia católica, el cristianismo, la existencia de Dios y la religiosidad en general con el que están salpicadas sus narraciones. Ahora bien, además de las citadas posturas antirreligiosas, ¿cómo se manifiesta estéticamente la desacralización de la novela en Vallejo?

Primero que nada, habría que señalar que algunos de los rasgos desacralizadores de la novelística de Vallejo son afines a los que se manifiestan en las novelas del posboom. Al igual que las novelas testimoniales y neosentimentales, las de Vallejo manifiestan un elevado subjetivismo y personalismo: su narradorprotagonista es en todas ellas ese "viejo dandy" egoísta, misántropo y prejuiciado, modelado sobre el discurso del decadentismo de fines del siglo XIX, que ha explorado recientemente con lucidez Juanita Aristizábal. De este modo, Vallejo da al traste con aquella pululación de personajes y con la impersonalidad cuasidivina de las novelas del boom que se derivaba, en última instancia, del célebre dictamen de Gustave Flaubert: "El autor en su libro debe ser como Dios en el universo: presente en todas partes y visible en ninguna" (173).

Otro rasgo fundamental de todas las novelas de Vallejo es la crítica del nacionalismo y de lo nacional, análoga a la que se inicia en las novelas testimoniales del posboom y que se ha incrementado en años más recientes en proyectos novelísticos como los emanados del grupo del Crack, en México, en los diversos autores que colaboraron con la antología MacOndo, en Chile, y en autores de la talla de Roberto Bolaño. Ya es famosa la aseveración de Vallejo de que: "Yo soy la memoria de Colombia y su conciencia y después de mí no sigue nada" (La virgen de los sicarios 21); esta reducción de la nación y sus símbolos al discurso de un narrador solipsista y egomaníaco efectivamente despoja a la idea de la nación de su trascendencia, fundada en lo colectivo, y la convierte en un espejismo sujeto a la fantasía de un individuo. 
Volviendo al personalismo o subjetivismo en la novelística de Vallejo, otro efecto de este, es paradójicamente el de hacer aún más visible la religión al hablar sobre ella negativamente de manera tan abierta y explícita. Como otros muchos célebres ateos, desde el marqués de Sade y Nietzsche hasta Luis Buñuel — quien, haciendo suyo un aforismo de Lichtenberg, aseveró: "Soy ateo, gracias a Dios"-, su ateísmo lleva a Vallejo a referirse con frecuencia a la religión y a hacerlo en la modalidad muy tradicional de la blasfemia. Para muestra, baste este botón de $E l$ desbarrancadero:

Nos amamos, gústele o no le guste a este Papa. A esta travestida polaca y a sus esbirros del Opus Dei y de la Compañía de Jesús, que Nuestro Señor Satanás acoja sin dilaciones en su caldero hirviendo. ¡O qué! ¿Va a dejar este Diablo idiota que se nos vaya impune a cantar al cielo semejante pandilla internacional de mafiosos? Si hay Dios tiene que haber un Diablo que cobre las cuentas sucias de este mundo y nos investigue de paso las de los bancos vaticanos, a ver si las encuentra tan católicas. Dios sí existe pero anda coludido con cuanto delicuente hay de cuello blanco en el planeta. Este viejo es como los presidentes colombianos: un alcahueta del delito, un desvergonzado, un indigno [...] Mientras Él exista existirán siempre aquí abajo, en este desventurado valle de lágrimas, el ecumenismo o globalización, la corrupción, la impunidad, la coima. El único que puede acabar con los cuatro jinetes del Apocalipsis es el Diablo. (176)

Con su invectiva sazonada de blasfemia, Vallejo pone al descubierto, a la vez que pone a prueba, el andamiaje religioso que, desde los tiempos del High Modernism, sustenta más o menos soterradamente a la novela moderna. Cuando el narrador vallejiano lanza una de sus muchas andanadas contra la deidad, está también denunciando, en términos estéticos, la aparente dependencia de la novelística moderna sobre una religiosidad que no se atreve a decir su nombre. Más aún, denuncia una religiosidad que ha sido utilizada, con cierto cinismo, a la manera de los "efectos especiales" cinematográficos, para hacer de la novela, tradicionalmente el género del desencanto y la desilusión desde Cervantes y el Balzac de Illusions perdues (1837), un género de engañosa magia y de efímera trascendencia. No en balde un destacado novelista colombiano actual, Santiago Gamboa, ha señalado a Fernando Vallejo como uno de los inspiradores de la más reciente novelística hispanoamericana, para la cual "los preferidos fueron los más alejados del realismo mágico: Sergio Pitol, César Aira, Fogwill, Fernando Vallejo, y en lo relativo a la novela negra, Paco Taibo II" (Gamboa, "De los noventa para acá"). 
Como puede apreciarse en el citado pasaje de El desbarrancadero, Vallejo no se preocupa sobremanera por las contradicciones, antinomias y paradojas a veces jocosas en las que incurre en sus blasfemias. Esto se explica porque su discurso narrativo se funda sobre la contra-dicción: es decir, el hablar en contra o en oposición sistemática a cualquier concepto, individuo o postura que él considere dominante. La estrategia de Vallejo es comparable a la de los llamados contrarios en ciertas naciones indígenas de Norteamérica, como los payasos heyoka entre los lakota y los guerreros "contrarios" de los cheyennes, los cuales, según los especialistas: "manifest a resistance to normative behavior. Their ritual clowning often entails doing daily tasks backward and speaking in seemingly nonsensical and inappropriate ways" (Crawford y Kelley 764-5). También es muy afín a la actitud de los filósofos cínicos de la Antigüedad, desde Diógenes hasta Menipo, cuya conducta anticonvencional y su práctica de la parresia - hablar siempre con absoluta franqueza, aun a costa de sus vidas - los convirtió en los rebeldes sociales arquetípicos del mundo antiguo (Branham y Goulet-Cazé; Foucault, Discourse and Truth). ${ }^{4}$

Resultaría simplista decir que el discurso vallejiano se basa en el principio de la "transgresión" que ha regido en la literatura moderna desde las vanguardias

4 Vale la pena señalar que en los pasados veinte años ha resurgido entre los teóricos y pensadores el interés por los cínicos de la Antigüedad. Pocos meses antes de su fallecimiento, en 1983, el pensador francés Michel Foucault anticipó esta revisión del cinismo antiguo al dictar una serie de charlas en la Universidad de Berkeley sobre los cínicos y el discurso de la verdad (Discourse and Truth). Cinco años después, el teórico alemán Peter Sloterdijk publicó un influyente estudio sobre el tema: Crítica de la razón cínica. El renovado interés en los cínicos surge en parte como respuesta a lo que algunos han visto como la acentuada tendencia en la cultura posmoderna hacia el cinismo en el sentido actual del término, que el Diccionario de la Real Academia Española define tajantemente como "Desvergüenza en el mentir o en la defensa y práctica de acciones o doctrinas vituperables". Ciertamente, hoy día llamamos cínico a todo aquel que descuenta los "altos" ideales como la justicia, la generosidad, el patriotismo, el amor y la santidad, pues considera que las personas son incorregiblemente egoístas y que la naturaleza humana es esencialmente malvada (Desmond viii). El cinismo clásico, sin embargo, sí tenía "altos" ideales y se fundaba precisamente en la creencia en la virtud innata del ser humano. Desaseados y deambulantes, pobres y protestones, los cínicos eran ascetas y rebeldes sociales que vagaban por las ciudades del mundo grecorromano como perros realengos: iban en medio del pueblo, pero sin formar parte de este, como perros guardianes potencialmente amistosos pero también como agresivos y rabiosos espíritus satíricos (Desmond viii). La desvergüenza de los cínicos era legendaria: es fama que Diógenes de Sinope se masturbaba en el ágora para luego exclamar: "¡Ojalá que frotándome el vientre se me quitase el hambre!” (Diógenes Laercio 341). Diógenes orinaba, defecaba, copulaba y comía en público (esto último tampoco era bien visto en la antigua Grecia), y así lo hacían también sus seguidores, los esposos Crates e Hiparquia, para escándalo de la sociedad de la época (Branham y Goulet-Cazé 9-10). 
históricas y que Octavio Paz bautizó con el nombre de la tradición de la ruptura. El objetivo de la transgresión ha sido siempre el de anular o ningunear aquello que se transgrede - llámese la ley, la naturaleza, o la deidad - para poder entonces afirmar el establecimiento de un nuevo principio, un nuevo comienzo. Hay una voluntad creadora o redentora - de índole en última instancia religiosa - en la transgresión vanguardista, que se podría resumir en el conocido verso de Vicente Huidobro: "El poeta es un pequeño Dios". En cambio, Vallejo realiza una "transgresión de la transgresión", pues no elimina el término que transgrede; por el contrario, se vale este, aunque lo despoja de su valor trascendente. Como dice en el pasaje antes citado: "Dios sí existe pero anda coludido con cuanto delicuente hay de cuello blanco en el planeta" (176).

Otra transgresión de la transgresión en Vallejo se da en su empecinada conservación de la gramática que, en gran medida, es una contra-dicción del postulado de Nietzsche al que aludí en el epígrafe: "Me temo que no nos libraremos de Dios mientras sigamos creyendo en la gramática...". Vallejo no solo no renuncia a la gramática, sino que se autoproclama en La virgen de los sicarios "el último gramático de Colombia" (58). Seguir la sugerencia de Nietzsche y escribir desatendiendo la gramática para así poder "librarse de Dios" — como lo intentaron los vanguardistas históricos con la escritura automática, las jitanjáforas y otros experimentos semejantes - desemboca en una escritura enigmática y alienada que renuncia a toda comunicación, lo cual no es, a todas luces, una de las metas de Vallejo.

$\mathrm{Al}$ principio de estas páginas propuse que uno de los aportes de Vallejo es el de intentar producir una narrativa profundamente desacralizada que se resista incluso a la tendencia moderna a hacer de los textos literarios - y particularmente las novelas - textos sagrados. Probablemente la principal estrategia de Vallejo para resistir a la sacralización es la ya mencionada técnica de la contra-dicción, asociada a su postura de sistemática contrariedad a todo lo que sea o parezca ser favorecido o desfavorecido por la mayoría de su público lector: así, el narrador vallejiano dice despreciar todo tipo de religión, además de la democracia y el populismo, la nación en general y en particular (es decir, Colombia), el sexo por procreación y la vida humana en general; por otra parte, afirma su ateísmo (aunque en los ambiguos términos de la blasfemia), su postura más egoísta que elitista ante las masas, su desarraigo, su pederastia, su amor por los animales y su nihilismo. No se trata en este caso, a mi parecer, de la simple y llana inversión de valores que han practicado los poetas y prosistas "malditos" de los siglos XIX y XX, desde Baudelaire hasta Jean Genet, la cual ha llevado a algunos a crear en torno a estos autores una sacralidad de signo negativo. Se trata, más bien, de 
una estrategia de "ofender a todos por igual" para no permitir que sus textos sean sacralizados — es decir, vistos como fuente de revelación- ni que su persona sea vista como la de un vates o un profeta. Inasible y mercurial como un Diablo Cojuelo, la escritura de Fernando Vallejo busca remontarse al instante inaugural en el cual la literatura empezó a darse cuenta de que está hecha, a la misma vez, de afirmaciones y de negaciones, de algo y de nada, y comenzó a descubrirse a sí misma, como afirmara Michel Foucault, en "el ser salvaje e imperioso de las palabras" (Las palabras y las cosas 313).

\section{Obras citadas}

Alonso, Carlos J. The Spanish American Regional Novel: Modernity and Authocthony. Cambridge: Cambridge University Press, 1990.

Aristizábal, Juanita. "Teología literaria en El desbarrancadero de Fernando Vallejo". Literatura: Teoría, Historia, Crítica 14 (2012): 93-119.

Berman, Marshall. All that Is Solid Melts into Air: The Experience of Modernity. Nueva York: Penguin Books, 1988.

Borges, Jorge Luis. Obras completas II. Buenos Aires: Emecé, 1996.

Branham, R. Bracht y Marie-Odile Goulet-Cazé. The Cynics: The Cynic Movement in Antiquity and Its Legacy. Berkeley: University of California Press, 1996.

Calasso, Roberto. La literatura y los dioses. Barcelona: Anagrama, 2003.

Crawford, Suzanne J. y Dennis F. Kelley. American Indian Religious Traditions: An Encyclopedia, vol. 1. Santa Barbara, CA: ABC-CLIO, 2005.

Desmond, William D. The Greek Praise of Poverty: Origins of Ancient Cynicism. Notre Dame, Indiana: University of Notre Dame Press, 2006.

Diógenes Laercio. Vidas, opiniones y sentencias de los filósofos más ilustres. Trad. José Ortiz y Sanz. Madrid: Luis Navarro, 1887.

Flaubert, Gustave. The Letters of Gustave Flaubert (1830-1857). Ed. Francis Steegmuller. Cambridge, MA: Harvard University Press, 1981.

Foucault, Michel. Discourse and Truth: The Problematization of Parrhesia. Lectures given by Michel Foucault at the University of California at Berkeley, Oct.-Nov. 1983. Web. 19 de enero del 2009.

-. Las palabras y las cosas. México: Siglo XXI, 1977.

Gamboa, Santiago. "De los noventa para acá". El País.

Babelia. Web. 27 de noviembre de 2011.

García Márquez, Gabriel. Cien años de soledad. Madrid: Espasa-Calpe, 1993. 
Gutiérrez-Mouat, Ricardo. "La narrativa latinoamericana del posboom". Revista Interamericana de Bibliografía/InterAmerican Review of Bibliography 38 (1988): 3-10.

Lewis, Pericles. Religious Experience and the Modernist Novel. Cambridge: Cambridge University Press, 2010.

Lucáks, Georg. Teoría de la novela. Barcelona: EDHASA, 1971.

Ortega y Gasset,José. Meditaciones del Quijote e Ideas sobre la novela. Madrid: Revista de Occidente, 1975.

Pellón, Gustavo. "The Spanish American Novel: Recent Developments, 1975 to $1990 "$ ". The Cambridge History of Latin American Literature, 2. Eds. Enrique Pupo-Walker y Roberto González Echevarría. Cambridge: Cambridge University Press, 1996. 279-302.

Pérez Firmat, Gustavo. Idle Fictions: The Hispanic Vanguard Novel, 1926-1934. Durham: N.C.: Duke University Press, 1982.

Shaw, Donald L. Antonio Skármeta and the Post-Boom. Hanover, NH: Ediciones del Norte, 1994.

-. The Post-Boom in Spanish American Fiction. New York: State University of New York Press, 1998.

Sloterdijk, Peter. Critique of Cynical Reason. Trad. Michael Eldred. Londres: Verso, 1988.

Vallejo, Fernando. El desbarrancadero. Madrid: Alfaguara, 2010.

-. La virgen de los sicarios. Madrid: Alfaguara, 1994.

Volpi, Jorge. El insomnio de Bolívar: cuatro consideraciones intempestivas sobre América Latina en el siglo XXI. Barcelona: Debate, 2009.

-. "El profeta de América Latina". Mentiras contagiosas.

Madrid: Páginas de Espuma, 2008. 173-176.

Woolf, Virginia. "Modern Fiction". Collected Essays II.

Londres: Hogarth Press, 1966. 104-107. 